\title{
Pendampingan Eksperimen Fisika Bagi Siswa-Siswa SMA di Surabaya
}

\author{
Elisabeth Pratidhina ${ }^{1 *}$, Kurniasari ${ }^{2}$, Budijanto Untung ${ }^{3}$, Herwinarso ${ }^{4}$, \\ Anthony Wijaya ${ }^{5}$, Bergitta Dwi Anawati ${ }^{6}$, Jane Koswojo ${ }^{7}$, Johanes VD \\ Wirjawan $^{8}$, Sugimin' \\ 1,2,3,4,5,6,7,8,9 Pendidikan Fisika, Universitas Katolik Widya Mandala Surabaya \\ Email: elisa.founda@ukwms.ac.id ${ }^{1}$ \\ *Corresponding author: Elisabeth Pratidhina
}

\begin{abstract}
ABSTRAK
Fisika adalah ilmu yang sangat erat dengan kehidupan sehari-hari dan menjadi tonggak perkembangan teknologi. Oleh sebab itu, mata pelajaran fisika diberikan pada siswa-siswa Sekolah Menengah Atas (SMA). Pembelajaran Fisika harusnya menekankan pada pengalaman langsung untuk mengembangkan kompetensi agar siswa mampu memahami fenomena alam. Hal ini akan membantu siswa untuk memperoleh pemahaman yang lebih mendalam. Akan tetapi, banyak sekolah-sekolah di Indonesia tidak memiliki peralatan yang cukup memadai untuk menunjang pembelajaran eksperimen, termasuk beberapa SMA di daerah Surabaya dan sekitarnya. Program Studi Pendidikan Fisika sebagai institusi yang mencetak calon guru-guru fisika perlu memberikan andil dalam mengatasi keterbatasan yang dimiliki oleh SMA-SMA di Surabaya dan sekitarnya. Program Studi Pendidikan Fisika memiliki peralatan dan sumber daya manusia yang cukup memadahi sehingga memungkinkan untuk mengadakan program pengabdian masyarakat berupa Pendampingan Eksperimen Fisika untuk Siswa-Siswa SMA. Program ini telah terlaksana sejak September 2018 hingga April 2019 melibatkan 14 sekolah mitra dengan jumlah siswa yang berpartisipasi sebanyak 1259 siswa. Kegiatan ini mendapatkan respon yang baik dari pihak sekolah, guru fisika, dan para siswa. Melalui kegiatan ini, keterbatasan peralatan eksperimen di sekolah cukup teratasi. Para siswa juga antusias sebab dengan kegiatan eksperimen pembelajaran fisika menjadi lebih menarik.
\end{abstract}

Kata Kunci: eksperimen fisika; pengabdian kepada masyarakat; sekolah menengah atas.

\section{ABSTRACT}

Physics is closely related to our daily life and becomes a fundamental subject for technology development. That is why physics is given to high school students. The physics learning process should emphasize direct experience to guide students in understanding phenomena in nature. The direct experiment will stimulate students to develop their in-depth knowledge. However, most schools in Indonesia, including in Surabaya, do not have adequate experiment apparatus to support that physics learning activity with experiments. Department of Physics Education, as an institute that educates pre-service physics teachers, should contribute to solving the limitation of some senior high schools in Surabaya. Department of Physics Education in Widya Mandala Catholic University has sufficient experiment facilities and human resources to conduct a community service program in the form of Physics Experiment Assistance for High School Students. The program has been conducted from September 2018 until April 2019. There are 14 schools attendinng this program, with 1259 students involved. This program gains positive responses from school principals, physics teachers, and students. Through this program, the limitation of several high schools in providing experiment facilities can be partially solved. Students who involve in this program are enthusiastic because, through experiments, physics learning activity becomes more interesting.

Keywords: community service; physics experiment; senior high school. 
Elisabeth Pratidhina ${ }^{1}$, Kurniasari ${ }^{2}$, Budijanto Untung ${ }^{3}$, Herwinarso ${ }^{4}$, Anthony Wijaya ${ }^{5}$, Bergitta Dwi Anawati ${ }^{6}$, Jane Koswojo ${ }^{7}$, Johanes VD Wirjawan ${ }^{8}$, Sugimin 9 /Aksiologiya: Jurnal Pengabdian Kepada Masyarakat. Vol.4, No.1, Februari 2020 Hal 78 - 85

\section{PENDAHULUAN}

Fisika merupakan salah satu ilmu dasar yang diperlukan bagi pemahaman dan penguasaan teknologi. Namun sangat disayangkan bahwa fisika merupakan salah satu mata pelajaran yang paling tidak disukai oleh siswa karena dirasa sulit. Sasaran utama semua cabang sains, termasuk fisika, adalah mencoba menemukan keteraturan di dalam observasi terhadap dunia di sekeliling kita. Salah satu aspek penting dalam sains adalah pengamatan atau observasi terhadap kejadian-kejadian, yang meliputi perancangan dan pelaksanaan eksperimen (Giancoli, 2014). Fisika adalah ilmu yang didasarkan pada pengamatan-pengamatan

eksperimental.

Pembelajaran Fisika perlu menekankan pada pengalaman langsung untuk mengembangkan kompetensi agar siswa mampu memahami alam sekitar melalui proses mencari tahu dan berbuat, hal ini akan membantu siswa untuk memperoleh pemahaman yang lebih mendalam. Keterampilan dalam menerapkan metode ilmiah untuk mengembangkan dan menemukan suatu pengetahuan atau memecahkan masalah dinamakan dengan keterampilan proses sains (Gagne, E. D., Yekovich, C. W., \& Yekovich, 1993). Keterampilan proses sains meliputi mengamati, menduga, mengukur, menggolongkan/ mengklasifikasi, memprediksi, dan mengkomunikasikan informasi dalam berbagai cara (Padilla, 1990). Keterampilan proses sains diyakini dapat memberikan pengalaman bermakna bagi siswa dan mengembangkan kemampuan berpikir tingkat tinggi bagi siswa (Amnah et al., 2013). Selain itu, pembelajaran dengan mengintegrasikan keterampilan proses sains berpotensi untuk mengembangkan kreativitas siswa (Aktamis, Faculty, \& Eyl, 2008).

Salah satu cara untuk mengembangkan keterampilan proses sains dalam pembelajaran fisika adalah melalui eksperimen atau aktivitas laboratorium secara inquiry (Mattheis \& Nakayama, 1988; Subekti \& Ariswan, 2016). Selain mengembangkan keterampilan proses sains, eksperimen juga berperan untuk membentuk keterampilan berpikir kritis, intuisi, logika dan kemampuan memecahkan masalah (Hofstein \& Lunetta, 1982). Kegiatan eksperimen di laboratorium juga dapat meningkatkan keaktifan peserta didik dalam pembelajaran dan menumbuhkan sikap positif peserta didik terhadap sains (Etkina, Van Heuvelen, Brookes, \& Mills, 2002; Tobin, Tobin, \& Australian, 2015)

Berdasarkan wawancara dengan guru-guru pengampu mata pelajaran Fisika, beberapa Sekolah Menengah Atas (SMA) di sekitar Surabaya dan Sidoarjo yang belum memiliki sarana laboratorium untuk eksperimen Fisika yang memadai. Kekurangannya terletak pada peralatan praktikum Fisika yang tidak lengkap, terutama untuk praktikum Fisika Modern. Tidak adanya sarana yang memadai untuk melakukan 
Elisabeth Pratidhina ${ }^{1}$, Kurniasari ${ }^{2}$, Budijanto Untung ${ }^{3}$, Herwinarso ${ }^{4}$, Anthony Wijaya ${ }^{5}$, Bergitta Dwi Anawati ${ }^{6}$, Jane Koswojo ${ }^{7}, J^{\prime}$ hanes VD Wirjawan ${ }^{8}$, Sugimin ${ }^{9}$ /Aksiologiya: Jurnal Pengabdian Kepada Masyarakat. Vol.4, No.1, Februari 2020 Hal 78 - 85

eksperimen atau pengamatan langsung pada pembelajaran fisika menyebabkan guru lebih banyak bercerita teori di dalam kelas dengan banyak pendekatan matematis. Hal tersebut menjadi salah satu penyebab siswa sering merasa bosan dalam pembelajaran fisika dan berpendapat bahwa fisika adalah pelajaran yang sukar.

Sebagai institusi pendidikan yang menghasilkan tenaga-tenaga guru fisika bagi sekolah menengah, Prodi Pendidikan Fisika Universitas Katolik Widya Mandala Surabaya mempunyai tanggung jawab sosial untuk membantu mengatasi permasalahan pendidikan fisika yang terjadi di sekolah menengah tersebut. Salah satu caranya adalah dengan memberikan pendampingan eksperimen fisika bagi siswa SMA di Surabaya dan sekitarnya, khususnya sekolah-sekolah dengan fasilitas laboratorium fisika yang terbatas. Mengingat fasilitas laboratorium fisika di Program Studi Pendidikan Fisika cukup lengkap bagi pembelajaran fisika untuk tingkat sekolah menengah, diharapkan siswasiswa yang memanfaatkannya akan terbantu memahami fisika dengan lebih baik, sehingga lebih termotivasi untuk menyenangi fisika.

\section{METODE PELAKSANAAN}

Pendampingan eksperimen

fisika di Laboratorium Fisika UKWMS bagi siswa-siswa SMA di Surabaya ini berlangsung sejak September 2018 hingga April 2019.
Program ini ditawarkan kepada SMASMA di Surabaya yang tertarik dan membutuhkan. Adapun tahapan pelaksanaan mulai dari proses persiapan hingga evaluasi diuraikan sebagai berikut.

1. Menyiapkan topik-topik praktikum beserta modulnya

2. Mempublikasikan kegiatan kepada SMA-SMA di Surabaya dan sekitarnya.

3. Mendata sekolah-sekolah yang hendak berpartisipasi menjadi mitra dan mengatur jadwal kunjungan sekolah.

4. Mendata topik eksperimen yang dipilih oleh sekolah mitra (sekolah mitra dapat memilih 3 topik eksperimen fisika dari daftar yang ditawarkan)

5. Menyiapkan peralatan yang diperlukan untuk eksperimen dan melakukan brifing tutor (pendamping kelompok). Tutor ini perlu dibrifing terlebih dahulu sebab selain terdiri dari tim pelaksana inti (dosen) juga melibatkan mahasiswa Program Studi Pendidikan Fisika UKWMS.

6. Kegiatan eksperimen fisika untuk siswa-siswa SMA di Laboratorium Fisika UKWMS.

7. Evaluasi kegiatan pendampingan eksperimen fisika untuk siswasiswa SMA di Laboratorium Fisika UKWMS

\section{HASIL DAN PEMBAHASAN}

Program pendampingan eksperimen fisika ini disosialisasikan kepada SMA-SMA di sekitar 
Elisabeth Pratidhina ${ }^{1}$, Kurniasari ${ }^{2}$, Budijanto Untung ${ }^{3}$, Herwinarso ${ }^{4}$, Anthony Wijaya ${ }^{5}$, Bergitta Dwi Anawati ${ }^{6}$, Jane Koswojo ${ }^{7}$, Johanes VD Wirjawan ${ }^{8}$, Sugimin ${ }^{9}$ Aksiologiya: Jurnal Pengabdian Kepada Masyarakat. Vol.4, No.1, Februari 2020 Hal 78 - 85

Surabaya yang membutuhkan.

Kegiatan pendampingan eksperimen

fisika di Laboratorium Fisika Universitas Katolik Widya Mandala Surabaya disambut baik oleh SMASMA di Surabaya dan sekitarnya. Total terdapat 14 sekolah yang berpartisipasi dengan jumlah siswa sebanyak 1259 siswa. Adapun sekolah yang berpartisipasi menjadi mitra kegiatan ini diantaranya adalah: SMAK St Yusuf Surabaya, SMA Dr Sutomo Surabaya, SMA Kr. Dharma Mulya Surabaya, SMA Cita Hati Surabaya, SMA Hang Tuah 4 Surabaya, SMA Gloria I Surabaya, SMAK Untung Suropati Krian, SMA Negeri 19 Surabaya, SMA Karitas III Surabaya, SMA 17 Agustus Surabaya, SMA Kartika Wijaya Surabaya, SMA Gloria II Surabaya, SMAK St Carolus Surabaya, dan SMA Masa Depan Cerah Surabaya. Kegiatan pendampingan eksperimen fisika ini berlangsung sejak September 2018 hingga April 2019, dengan rincian kegiatan ditunjukkan pada Tabel 1

Pada setiap kegiatan, umumnya siswa melakukan 3 judul percobaan. Tim pelaksana menawarkan setidaknya 41 judul praktikum pilihan untuk dapat dipilih oleh pihak sekolah. Adapun eksperimen yang terlaksana di tahun pelaksanaan ini ada 22 judul, diantaranya sebagai berikut.

1. Jatuh Bebas

2. Gaya Angkat ke Atas (Archimedes)

3. Kalor Lebur Es

4. Transformator (Trafo)
5. Lissajous

6. Interferensi Young

7. Efek Fotolistrik

8. Rangkaian Listrik AC RLC Seri

9. Generator van de Graff

10. Jembatan Wheatstone

11. Boyle Gay-Lussac

12. Meja Gaya

13. Pipa U

14. Koefisien Gesekan,

15. Ripple Tank

16. Alat Ukur

17. Hukum Ohm

18. Solenoida

19. Defleksi Elektron

20. Piknometer

21. Lensa

22. Kisi Difraksi

Kegiatan yang diikuti oleh siswa terjadwal dari pukul 08.20-13.00, dengan rincian kegiatan berupa: pembukaan, eksperimen 1, eksperimen 2, eksperimen 3, dan penutup. Pada sesi pembukaan, siswa yang mengikuti kegiatan ini dibagi menjadi 3 kelompok besar (kloter) yang akan rolling bergantian melakukan eksperimen 1, 2, dan 3 di ruangan yang berbeda. Kloter tersebut dibagi-bagi lagi menjadi kelompok kecil untuk melakukan eksperimen. Setiap kelompok kecil memiliki tutor pendamping yang mengawasi dan mendampingi berjalannya eksperimen. Setelah eksperimen, juga dilakukan pembahasan. Pada sesi penutup dilakukan sharing kesan dan pesan dari para peserta dan doa penutup.

Para guru pendamping menyampaikan bahwa kegiatan eksperimen di Laboratorium Fisika ini 
Elisabeth Pratidhina ${ }^{1}$, Kurniasari ${ }^{2}$, Budijanto Untung ${ }^{3}$, Herwinarso ${ }^{4}$, Anthony Wijaya ${ }^{5}$, Bergitta Dwi Anawati ${ }^{6}$, Jane Koswojo ${ }^{7}$, Johanes VD Wirjawan $^{8}$, Sugimin ${ }^{9}$ Aksiologiya: Jurnal Pengabdian Kepada Masyarakat. Vol.4, No.1, Februari 2020 Hal 78 - 85

sangat bermanfaat untuk siswa. Fakta di lapangan, peralatan eksperimen di SMA sangatlah terbatas. Padahal pembelajaran fisika mestinya dapat menjadi sarana bagi siswa untuk melatih inkuiri dan berpikir kritisnya melalui eksperimen. Dengan adanya kegiatan pendampingan eksperimen ini, cukup membantu keterbatasan peralatan eksperimen di sekolah. Para siswa juga antusias mengikuti kegiatan ini. Menurut mereka, pembelajaran melalui eksperimen lebih menarik dan tidak membosankan. Selain itu, kegiatan kunjungan laboratorium juga memberikan wawasan bagi siswa SMA mengenai pendidikan tinggi di universitas khususnya bagi siswa kelas XII.

Selain 14 sekolah mitra yang mengikuti kegiatan ini, beberapa sekolah yang mendengar adanya kegiatan ini pun menyampaikan ketertarikannya dan menghubungi Prodi Pendidikan Fisika UKWMS untuk mendaftar. Akan tetapi, dikarenakan keterbatasan waktu dan sumber daya, kami belum mampu memberikan layanan kepada setiap sekolah. Sebagai tindak lanjutnya, kami berencana untuk melanjutkan kegiatan ini di tahun mendatang, dan menjadikan sekolah-sekolah yang belum berkesempatan tersebut sebagai prioritas sekolah mitra pada program di tahun mendatang.

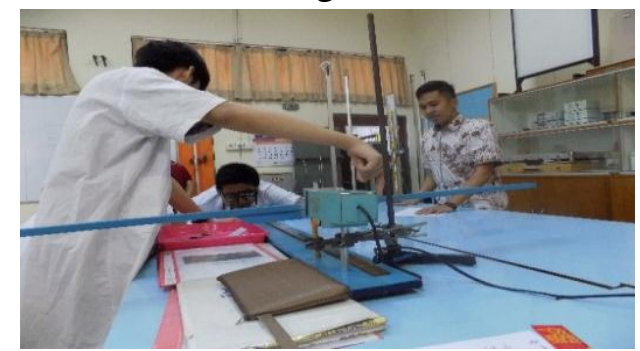

Gambar 1. Dokumentasi eksperimen kisi difraksi oleh siswa sma kr. Dharma mulya surabaya

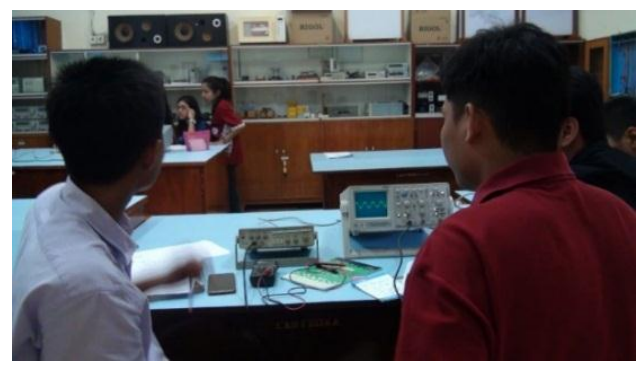

Gambar 2. Siswa SMAK St Yusuf sedang bereksperimen menggunakan Oscilloscope, salah satu alat yang jarang dimiliki oleh SMA

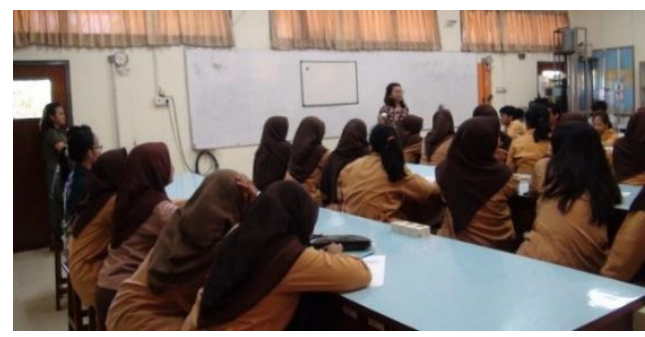

Gambar 3. Dokumentasi Sesi Penutup

Tabel 1. Rincian Kegiatan Pendampingan Eksperimen Fisika Bagi Siswa-Siswa SMA di Surabaya

\begin{tabular}{|c|l|c|l|c|}
\hline No & Hari, Tanggal & Sekolah & \multicolumn{1}{|c|}{ Judul Praktikum } & $\begin{array}{c}\text { Jumlah } \\
\text { siswa }\end{array}$ \\
\hline 1 & $\begin{array}{l}\text { Jumat, 7 } \\
\text { September 2018 }\end{array}$ & SMAK St Yusuf & $\begin{array}{l}\text { Jatuh Bebas, Gaya ke Atas, Kalor } \\
\text { Lebur Es }\end{array}$ & 30 \\
\hline 2 & $\begin{array}{l}\text { Jumat, 14 } \\
\text { September 2018 }\end{array}$ & SMA Dr Sutomo & $\begin{array}{l}\text { Transformator, Lissayous, } \\
\text { Interferensi Young }\end{array}$ & 68 \\
\hline
\end{tabular}


Elisabeth Pratidhina ${ }^{1}$, Kurniasari ${ }^{2}$, Budijanto Untung ${ }^{3}$, Herwinarso ${ }^{4}$, Anthony Wijaya ${ }^{5}$, Bergitta Dwi Anawati ${ }^{6}$, Jane Koswojo ${ }^{7}$, Johanes VD Wirjawan ${ }^{8}$, Sugimin ${ }^{9}$ /Aksiologiya: Jurnal Pengabdian Kepada Masyarakat. Vol.4, No.1, Februari 2020 Hal 78 - 85

\begin{tabular}{|c|c|c|c|c|}
\hline No & Hari, Tanggal & Sekolah & Judul Praktikum & $\begin{array}{l}\text { Jumlah } \\
\text { siswa }\end{array}$ \\
\hline 3 & $\begin{array}{l}\text { Jumat, } 21 \\
\text { September } 2018\end{array}$ & SMA Dr Sutomo & $\begin{array}{l}\text { Interferensi Young, Effek } \\
\text { Fotolistrik, RLC Seri }\end{array}$ & 86 \\
\hline 4 & $\begin{array}{l}\text { Jumat, } 28 \\
\text { September } 2018\end{array}$ & $\begin{array}{l}\text { SMA Kr. Dharma } \\
\text { Mulia }\end{array}$ & $\begin{array}{l}\text { Generator van de Graff, Jembatan } \\
\text { Whetstone, Transformator }\end{array}$ & 24 \\
\hline 5 & $\begin{array}{l}\text { Jumat, } 5 \text { Oktober } \\
2018\end{array}$ & SMAK St Yusuf & $\begin{array}{l}\text { Jembatan Wheatstone, Lissayous, } \\
\text { Efek Fotolistrik }\end{array}$ & 34 \\
\hline 6 & $\begin{array}{l}\text { Jumat, } 12 \\
\text { Oktober } 2018\end{array}$ & $\begin{array}{l}\text { SMA Cita Hati } \\
\text { (East) Sby }\end{array}$ & $\begin{array}{l}\text { Boyle Gay-Lussac, Meja Gaya, } \\
\text { Generator van de Graff }\end{array}$ & 48 \\
\hline 7 & $\begin{array}{l}\text { Jumat, } 26 \\
\text { Oktober } 2018\end{array}$ & SMAK St Yusuf & $\begin{array}{l}\text { Jatuh Bebas, Gaya ke Atas, Kalor } \\
\text { Lebur Es }\end{array}$ & 33 \\
\hline 8 & $\begin{array}{l}\text { Sabtu, } 27 \\
\text { Oktober } 2018\end{array}$ & SMA Hang Tuah 4 & $\begin{array}{l}\text { Meja Gaya, Pipa U, Interferensi } \\
\text { Young }\end{array}$ & 63 \\
\hline 9 & $\begin{array}{l}\text { Jumat, } 2 \\
\text { November } 2018\end{array}$ & $\begin{array}{l}\text { SMA Gloria I } \\
\text { Surabaya }\end{array}$ & $\begin{array}{l}\text { Efek fotolistrik, Pipa U, Arus } \\
\text { Bolak-Balik RLC }\end{array}$ & 17 \\
\hline 10 & $\begin{array}{l}\text { Sabtu, } 3 \\
\text { November } 2018\end{array}$ & $\begin{array}{l}\text { SMAK Untung } \\
\text { Suropati Krian }\end{array}$ & $\begin{array}{l}\text { Koefisien Gesekan, Kalor Lebur } \\
\text { Es, Interferensi Young }\end{array}$ & 93 \\
\hline 11 & $\begin{array}{l}\text { Sabtu, } 10 \\
\text { November } 2018\end{array}$ & $\begin{array}{l}\text { SMA Negeri } 19 \\
\text { Surabaya }\end{array}$ & $\begin{array}{l}\text { Generator Van de Graf, Ripple } \\
\text { Tank, Efek Fotolistrik }\end{array}$ & 81 \\
\hline 12 & $\begin{array}{l}\text { Sabtu, } 16 \\
\text { November } 2018\end{array}$ & $\begin{array}{l}\text { SMA Karitas III } \\
\text { Surabaya }\end{array}$ & $\begin{array}{l}\text { Meja Gaya, Koefisien Gesekan, } \\
\text { Neraca Mohr }\end{array}$ & 32 \\
\hline 13 & $\begin{array}{l}\text { Sabtu, } 17 \\
\text { November } 2018\end{array}$ & $\begin{array}{l}\text { SMA Negeri } 19 \\
\text { Surabaya }\end{array}$ & $\begin{array}{l}\text { Generator Van de Graf, Ripple } \\
\text { Tank, Efek Fotolistrik }\end{array}$ & 40 \\
\hline 14 & $\begin{array}{l}\text { Jumat, } 23 \\
\text { November } 2018\end{array}$ & $\begin{array}{l}\text { SMA } 17 \text { Agustus } \\
\text { Surabaya }\end{array}$ & $\begin{array}{l}\text { Generator Van de Graff, } \\
\text { Rangkaian RLC }\end{array}$ & 50 \\
\hline 15 & $\begin{array}{l}\text { Jumat, } 30 \\
\text { November } 2018\end{array}$ & $\begin{array}{c}\text { SMA Kartika } \\
\text { Wijaya Surabaya }\end{array}$ & $\begin{array}{l}\text { Alat Ukur, Hukum Ohm, } \\
\text { Interferensi Young }\end{array}$ & 51 \\
\hline 16 & $\begin{array}{l}\text { Sabtu, } 1 \\
\text { Desember } 2018\end{array}$ & $\begin{array}{l}\text { SMA Negeri } 19 \\
\text { Surabaya }\end{array}$ & $\begin{array}{l}\text { Generator Van de Graf, Ripple } \\
\text { Tank, Efek Fotolistrik }\end{array}$ & 71 \\
\hline 17 & $\begin{array}{l}\text { Jumat, } 17 \\
\text { Desember } 2018\end{array}$ & $\begin{array}{l}\text { SMAK St Carolus } \\
\text { Surabaya }\end{array}$ & $\begin{array}{l}\text { Solenoida, Arus Bolak-Balik } \\
\text { RLC Seri, Defleksi Elektron }\end{array}$ & 68 \\
\hline 18 & $\begin{array}{l}\text { Sabtu, } 8 \\
\text { Desember } 2018\end{array}$ & $\begin{array}{l}\text { SMA Negeri } 19 \\
\text { Surabaya }\end{array}$ & $\begin{array}{l}\text { Generator Van de Graf, Ripple } \\
\text { Tank, Efek Fotolistrik }\end{array}$ & 72 \\
\hline 19 & $\begin{array}{l}\text { Senin, } 7 \text { Januari } \\
2019\end{array}$ & $\begin{array}{l}\text { SMA Karitas III } \\
\text { Surabaya }\end{array}$ & $\begin{array}{l}\text { Efek Fotolistrik, Defleksi } \\
\text { Elektron, Generator van de Graff }\end{array}$ & 35 \\
\hline 20 & $\begin{array}{l}\text { Selasa, } 8 \text { Januari } \\
2019\end{array}$ & $\begin{array}{l}\text { SMA Karitas III } \\
\text { Surabaya }\end{array}$ & $\begin{array}{l}\text { Interferensi Young, Kisi Difraksi, } \\
\text { Polarisasi }\end{array}$ & 27 \\
\hline 21 & $\begin{array}{l}\text { Jumat, } 18 \\
\text { Januari } 2019\end{array}$ & SMA Gloria II & $\begin{array}{l}\text { Defleksi Elektron, Boyle, } \\
\text { Interferensi Young }\end{array}$ & 62 \\
\hline 22 & $\begin{array}{l}\text { Jumat, } 25 \\
\text { Januari } 2019\end{array}$ & $\begin{array}{l}\text { SMA } 17 \text { Agustus } \\
\text { Surabaya }\end{array}$ & Piknometer, Hukum Boyle & 36 \\
\hline 23 & $\begin{array}{l}\text { Jumat, } 8 \\
\text { Februari } 2019\end{array}$ & $\begin{array}{l}\text { SMA } 17 \text { Agustus } \\
\text { Surabaya }\end{array}$ & $\begin{array}{l}\text { Generator Van de Graff, } \\
\text { Rangkaian RLC }\end{array}$ & 70 \\
\hline
\end{tabular}


Elisabeth Pratidhina ${ }^{1}$, Kurniasari ${ }^{2}$, Budijanto Untung ${ }^{3}$, Herwinarso ${ }^{4}$, Anthony Wijaya ${ }^{5}$, Bergitta Dwi Anawati ${ }^{6}$, Jane Koswojo ${ }^{7}$, Johanes VD Wirjawan ${ }^{8}$, Sugimin'/Aksiologiya: Jurnal Pengabdian Kepada Masyarakat. Vol.4, No.1, Februari 2020 Hal 78 - 85

\begin{tabular}{|c|l|c|l|c|}
\hline No & Hari, Tanggal & Sekolah & Judul Praktikum & $\begin{array}{c}\text { Jumlah } \\
\text { siswa }\end{array}$ \\
\hline 24 & $\begin{array}{l}\text { Jumat, 22 } \\
\text { Februari 2019 }\end{array}$ & $\begin{array}{c}\text { SMA Dharma } \\
\text { Mulya Surabaya }\end{array}$ & $\begin{array}{l}\text { Ripple Tank. Kisi Difraksi, } \\
\text { Interferensi Young }\end{array}$ & 22 \\
\hline 25 & $\begin{array}{l}\text { Jumat, 8 Maret } \\
2019\end{array}$ & $\begin{array}{c}\text { SMA Masa Depan } \\
\text { Cerah Surabaya }\end{array}$ & Lensa, Solenoida, Kisi Difraksi & 41 \\
\hline 26 & $\begin{array}{l}\text { Jumat, 26 April } \\
2019\end{array}$ & $\begin{array}{c}\text { SMA 17 Agustus } \\
\text { Surabaya }\end{array}$ & Piknometer, Jatuh Bebas & 32 \\
\hline \multicolumn{2}{|c|}{ JUMLAH SISWA } & $\mathbf{1 2 5 9}$ \\
\hline
\end{tabular}

\section{SIMPULAN}

Program pengabdian kepada masyarakat berupa layanan praktikum bagi siswa SMA di Laboratorium Fisika Universitas Katolik Widya Mandala telah terlaksana sejak September 2018 hingga April 2019 melibatkan 14 sekolah mitra dengan jumlah siswa yang berpartisipasi sebanyak 1259 siswa. Kegiatan ini mendapatkan respon yang baik dari pihak sekolah, guru fisika, dan para siswa. Melalui kegiatan ini, keterbatasan peralatan eksperimen di sekolah dapat sedikit teratasi. Para siswa juga antusias sebab dengan kegiatan eksperimen, pembelajaran fisika dapat lebih menarik. Selain itu, para siswa juga mendapatkan tambahan wawasan mengenai pendidikan tinggi di universitas.

\section{UCAPAN TERIMAKASIH}

Tim mengucapkan terimakasih kepada Universitas Katolik Widya Mandala Surabaya yang telah mendanai Program Pengabdian kepada Masyarakat ini dan kepada laboran, Bapak Agus dan tutor yang telah membantu pelaksanaan kegiatan.

\section{DAFTAR PUSTAKA}

Aktamis, H., Faculty, A. M., \& Eyl, D. (2008). The effect of scientific process skills education on students' scientific creativity, science attitudes and academic achievements. Asia-Pacific Forum on Science Learning and Teaching, 9(1), 1-21.

Amnah, R., Rauf, A., Rasul, M. S., Mansor, A. N., Othman, Z., \& Lyndon, N. (2013). Inculcation of Science Process Skills in a Science Classroom. Asian Social Science, 9(8), 47-57. https://doi.org/10.5539/ass.v9n8 p47

Etkina, E., Van Heuvelen, A., Brookes, D. T., \& Mills, D. (2002). Role of Experiments in Physics Instruction - A Process Approach. The Physics Teacher, 40(6), 351-355. https://doi.org/10.1119/1.151159 2

Gagne, E. D., Yekovich, C. W., \& Yekovich, F. R. (1993). The cognitive psychology of school learning. New York: Harper Collins College Publishers.

Giancoli, D. C. (2014). Fisika: Prinsip dan Aplikasi (terjemahan). 
Elisabeth Pratidhina ${ }^{1}$, Kurniasari ${ }^{2}$, Budijanto Untung ${ }^{3}$, Herwinarso ${ }^{4}$, Anthony Wijaya ${ }^{5}$, Bergitta Dwi Anawati ${ }^{6}$, Jane Koswojo ${ }^{7}$, Johanes VD Wirjawan ${ }^{8}$, Sugimin'/Aksiologiya: Jurnal Pengabdian Kepada Masyarakat. Vol.4, No.1, Februari 2020 Hal 78 - 85

Jakarta: Erlangga.

Hofstein, A., \& Lunetta, V. N. (1982). The Role of the Laboratory in Science Teaching: Neglected Aspects of Research. Review of Educational Research, 52(2), 201-217. https://doi.org/10.3102/0034654 3052002201

Mattheis, F. E., \& Nakayama, G. (1988). Effects of a LaboratoryCentered Inquiry Program on Laboratory Skills, Science Process Skills, and Understanding of Science Knowledge in Middle Grades Students. ERIC Document Reproduction Service, No. ED 307.

Padilla, M. J. (1990). The Science Process Skills. Research Matters - to the Science Teacher, 9004.

Subekti, Y., \& Ariswan, A. (2016). Pembelajaran Fisika dengan Metode Eksperimen untuk Meningkatkan Hasil Belajar Kognitif dan Keterampilan Proses Sains The Physics Learning with Experimental Methods to Increase Cognitive
Aspects of Learning Outcomes and Science Process Skills. Jurnal Inovasi Pendidikan Fisika, 2(2), 252-261.

Tobin, K., Tobin, K., \& Australian, W. (2015). Secondary science laboratory activities Secondary science laboratory activities. Europian Journal of Science Education, $\quad 5284$ (October). https://doi.org/10.1080/0140528 860080208 